\title{
RESULTADOS DO INQUÉRITO ALIMENTAR REALIZADO NAS CIDADES DE APIAÍ, RIBEIRA E BARRA DO CHAPÉU (SÃO PAULO, BRASIL)*
}

Miguel, M. \& BoN, A. M. X. - Resultados do inquérito alimentar realizado nas cidades de Apiai, Ribeira e Barra do Chapéu (Säo Paulo, Brasil). Rev. Saúde públ., S. Paulo, 8: 75-86,1974.

RESUMo: Foram apresentados os resultados do inquérito alimentar realizado na regiäo do Vale do Ribeira, nas cidades de Apiai, Ribeira e Barra' do Chapéu (São Paulo, Brasil), em amostra constituída por 154 famílias, totalizando 939 indivíduos. O método utilizado para o levantamento foi o de pesagem "um dia sete dias". A análise dos dados evidenciou que em Apiai as adequaçóes médias de proteina, ferro e niacina foram as únicas que ultrapassaram os $100 \%$ dos valores recomendados, enquanto que, na cidade de Barra do Chapéu este fato ocorreu em relação à ferro, niacina $e$ vitamina $B_{1}$. Com referência à cidade de Ribeira, apenas niacina atingiu uma adequação de $100 \%$, sendo que os demais nutrientes apresentaram resultados inferiores.

UNITERMos: Inquérito alimentar*; São Paulo (Brasil)*.

\section{N T R O D U Ç A}

A maior parte da população do Vale do Ribeira, região localizada ao sul do Estado de São Paulo e delimitada pelas cristas da Serra Paranapiacaba, do Mar e Mongaguá, vive na zona rural com um baixo padrão de vida ${ }^{4}$.

0 homem da região dedica-se, principalmente, a atividades agrícolas, pesca, mineração e exploração do turismo, po- rém, as possibilidades econômicas ainda não foram bẹ compreendidas por ele, que necessita muito do trabalho de extensão educacional em todos os sentidos e do trabalho de extensão agrícola ${ }^{4}$.

Com a finalidade de conhecer os hábitos alimentares da região e desenvolver programas de Educação Alimentar, o Departamento de Nutrição da Faculdade de

- Trabalho apresentado no 6.0 Congresso Brasileiro de Nutricionistas; 3.0 Congresso Brasileiro de Nutrição e $1^{a}$ Reunião Brasileira sobre a Formação de Nutricionistas, São Paulo, 1972.

** Do Departamento de Nutrição da Faculdade de Saúde Pública da Universdiade de São Paulo - Av. Dr. Arnaldo, 715 - São Paulo, SP -- Brasil. 
MIGUEL, M. \& BON, A. M. X. - Resultados do inquérito alimentar realizado nas cidades de Apial, Ribeira e Barra do Chapéu (São Paulo, Brasil). Rev. Saúde públ., S. Paulo, 8: 75-86, 1974.

Saúde Pública da Universidade de São Paulo se propos em 1968, a fazer um levantamento da situação alimentar da referida região.

o Vale do Ribeira está assim dividido: ${ }^{4}$

\section{Alto Ribeira :}

Apiaí

Iporanga

Ribeira

Médio e Baixo Ribeira:

Cananéia

Eldorado

Iguape

Jacupiranga

Pariquera-Açu

Registro

Sete Barras

Vale do São Lourenço e Juquiá-Guaçu:

Juquiá

Miracatu

Pedro de Toledo

Itariri

Já foram feitos estudos sobre alimentação em Cananéia, Iguape, Jacupiranga, Pariquera-Açu, Itariri, Miracatu, Pedro de Toledo, Apiaí, Barra do Chapéu e Ribeira, portanto em municípios das 3 subregiōes.

No presente trabalho, apresentamos os resultados obtidos em Apiaí, Ribeira e Barra do Chapéu (Distrito de Apiaí) em levantamento realizado em outubro de 1970 pelo Departamento de Nutrição da Faculdade de Saúde Pública da Universidade de São Paulo, com a participação dos alunos do Curso de Graduação de Nutricionistas e do então Curso de PósGraduação com ênfase em Nutrição, dessa mesma Faculdade.
O B J E T I V O S

Os objetivos do inquérito alimentar foram de levantar dados sobre hábitos alimenares e consumo de alimentos na área, avaliando a dieta da população.

O objetivo principal do Departamento de Nutrição na realização deste levantamento foi o de treinar os alunos dos cursos já mencionados, capacitando-os para o desenvolvimento de programas de $\mathrm{Nu}$ trição em comunidades.

\section{DESCRICAO DA AREA}

A área de Apiaí abrange os municípios de Apiaí, Ribeira, Iporanga e Barra do Turvo ${ }^{4}$. A sede municipal de Apiaí está localizada a $247 \mathrm{~km}$ da Capital, a $1.050 \mathrm{~m}$ de altitude, fazendo limite com Itararé, Iporanga, Ribeira e Ribeirão Branco ${ }^{1}$. Ribeira - dista da Capital Estadual, em linha reta, $269 \mathrm{~km}$ e está a $150 \mathrm{~m}$ do nível do $\operatorname{mar}^{2}$ e Barra do Chapéu a $28 \mathrm{~km}$ da sede, Apiaí ${ }^{4}$.

Embora a agricultura seja mal desenvolvida devido ao relevo acidentado, à baixa fertilidade dos solos e à falta de estradas, encontramos no municipio de Apiai, culturas de tomate; em Barra do Chapéu, de tomate, repolho e abóbora e em Ribeira, de mamão, milho e em menor escala de cana de açúcar ${ }^{4}$.

Quanto às vias de comunicação contam apenas com a estrada asfaltada RibeiraCapão Bonito ${ }^{4}$, sendo que as demais estão em condições precárias, como por exemplo a que liga o município de Apiaí a Barra do Chapéu, que não é trafegável em periodos de chuva 4 .

As condições climáticas dessa região ainda estão por serem pesquisadas, pois não existem dados adequados. No entanto, sabemos que em Apiai, a pluviosidade é grande, o céu bastante nublado, o que 
MIGUEL, M. \& BON, A. M. X. - Resultados do ínquérito alimentar realizado nas cidades de Aplai, Ribeira e Barra do Chapéu (São Paulo, Brasil). Rev. Saúde públ., S. Paulo, 8: 75-86, 1974.

encurta o período de insolaçāo. As geadas de inverno também são freqüentes ${ }^{4}$.

As fontes supridoras da região do Alto Ribeira se localizam em Itapeva, Sorocaba, Itapetininga e na Capital do Estado. As granjas e fazendas abastecem em pequena quantidade as localidades. de aves e ovos. O leite é quase inexistente e o maior produtor é o distrito do Município de Apiaí, denominado Itaoca 4 .

Segundo o censo de 1970, encontramos no Distrito de Apiaí, uma população de 9.257 habitantes; no de Barra do Chapéu 3.328 e no de Ribeira 4.521, sendo que destes totais, pertencem a população urbana, respectivamente, $4.078,519$ e 432 habitantes ${ }^{3}$.

As condições de ensino não se apresentam satisfatórias, embora existam na subregião do Alto Ribeira, cursos primário, ginasial e comercial, há um deficit de professores formados, tanto nos cursos primários, como nos secundários. Isso faz com que $o$ analfabetismo persiga o homem da região, o qual se vê limitado em suas funções, em virtude da sua baixa condição de preparo ${ }^{4}$.

\section{A MOSTRAGE M}

Para a escolha das cidades onde seria realizado o inquérito alimentar, fez-se levantamento em 7 localidades da Região do Vale do Ribeira (Apiaí, Barra do Chapéu, Ribeira, Araçaíba, Itaoca, Iporanga e Lageado), sendo as 3 primeiras cidades as que apresentaram melhores condições para o desenvolvimento do trabalho, pois Apiaí possuia uma população de tamanho ideal para retirada de amostra que apresentasse resultados fidedignos dentro de tempo determinado, além de ser a única que oferecia condições de acomodação para toda equipe. Ribeira, por ser localidade com características econômicas diferentes de Apiai, estar próxima da cidade que seria a sede do grupo e também por ser grande produtora de mamão - fruta rica em Vitamina $A$, proporcionando a possibilidade de se verificar a influência desse fator sobre o consumo do referido nutriente na alimentação dessa comunidade. Finalmente, Barra do Chapéu, por sua população heterogênea composta de grupos vulneráveis numerosos, economia de subsistência e por situar-se próximo à cidade sede da equipe.

0 inquérito foi realizado na zona urbana das cidades escolhidas, retirando-se da população uma amostra casual simples, que correspondeu a 98 famílias em Apiaí (15\%), 28 em Ribeira (18\%) e 28 em Barra do Chapéu (18\%).

\section{TECNICA EMPREGADA NO INQUERITO ALIMENTAR}

Para a obtenção dos dados, utilizou-se o método das pesagens "um dia sete dias", que consiste no levantamento da alimentação de um dia por família amostrada, cobrindo o período de uma semana, com a finalidade de conhecer a variação semanal dos alimentos consumidos na comunidade.

\section{MATERIAL USADO}

Para a pesagem e medida dos alimentos e pessoas, foi utilizado o seguinte material:

- canecas graduadas de $10 \mathrm{em} 10 \mathrm{ml}$;

- balança para alimento com capacidade de $2 \mathrm{~kg}$ subdividida em $50 \mathrm{~g}$;

- balança para alimento com capacidade de $500 \mathrm{~g}$ subdividida em $10 \mathrm{~g}$;

- balança para pesar indivíduos com capacidade de $120 \mathrm{~kg}$ subdividida em $500 \mathrm{~g}$; 
MIGUEL, M. \& BON, A. M. X. - Resultados do inquérito alimentar realizado nas cldades de Aplal, Ribelra e Barra do Chapéu (São Paulo, Brasil). Rev. Saúde públ., S. Paulo, 8: 75-86, 1974.

- trena de $2 \mathrm{~m}$ subdividida em milímetros;

- esquadros.

\section{COMPOSICAOO POPULACIONAL}

Apiai - Das 98 famílias que participaram da amostra, num total de 566 pessoas, $49,8 \%$ pertenciam ao sexo masculino e $50,2 \%$ pertenciam ao sexo feminino. Em média, encontramos 6 pessoas por família. (Tabela 1)

Ribeira - Dos 197 habitantes, 51,0\% eram do sexo masculino e $49,0 \%$ do sexo feminino, perfazendo um total de 28 famílias que compuseram a amostra, dando em média 7 pessoas por família. (Tabela 2)

Barra do Chapéu - Nas 28 famílias visitadas, encontrou-se em média 6 indivíduos por familia, num total de $176 \mathrm{ha}$ bitantes que fizeram parte da amostra, sendo $53,4 \%$ do sexo masculino e $46,6 \%$ do sexo feminino. (Tabela 3 ).

RESULTA D O S

A relação dos alimentos consumidos nas cidades de Apiaí, Ribeira e Barra do Chapéu encontram-se na Tabela 4 .

TABELA 1

Distribuição populacional da amostra, segundo idade e sexo, zona urbana de Apial - 1970

\begin{tabular}{|c|c|c|c|c|c|}
\hline \multirow{2}{*}{\multicolumn{2}{|c|}{ Grupo etárıo }} & \multicolumn{2}{|c|}{ Sexo } & \multicolumn{2}{|c|}{ Total } \\
\hline & & masculino & feminino & n. ${ }^{\circ}$ de ind. & $\%$ \\
\hline 1 & 1 - 4 meses & 1 & - & 1 & 0,2 \\
\hline 4 & $1-12$ meses & 4 & 1 & 5 & 0,9 \\
\hline 1 & $1-4$ anos & 29 & 22 & 51 & 9,0 \\
\hline 4 & 1 - 7 anos & 25 & 17 & 42 & 7,4 \\
\hline 7 & 1 - 10 anos & 35 & 22 & 57 & 10,1 \\
\hline 10 & $1-13$ anos & 29 & 29 & 58 & 10,2 \\
\hline 13 & $1-16$ anos & 25 & 31 & 56 & 9,9 \\
\hline & $1-20$ anos & 19 & 36 & 55 & 9,7 \\
\hline 20 & $1-30$ anos & 38 & 50 & 88 & 15,5 \\
\hline & $1-40$ anos & 30 & 37 & 67 & 11,8 \\
\hline & $1-50$ anos & 20 & 20 & 40 & 7,1 \\
\hline & $1-60$ anos & 13 & 9 & 22 & 3,9 \\
\hline 60 & $1-70$ anos & 7 & 8 & 15 & 2,7 \\
\hline & $1-80$ anos & 5 & 2 & 7 & 1,2 \\
\hline & $1-90$ anos & 2 & - & 2 & 0,4 \\
\hline \multicolumn{2}{|c|}{ Total } & $\begin{array}{l}282 \\
49,8 \%\end{array}$ & $\begin{array}{l}284 \\
50,2 \%\end{array}$ & 566 & $100,0 \%$ \\
\hline
\end{tabular}


MIGUEL. M. \& BON. A. M. X. - Resultados do inquérito alimentar realizado nas cidades de Apiai, Ribeira e Barra do Chapéu (São Paulo, Brasil). Rev. Saúde públ., S. Paulo, 8: 75-86, 1974.

TABELA 2

Distribuição populacional da amostra, segundo idade e sexo, zona urbana de Ribeira -1970

\begin{tabular}{|c|c|c|c|c|c|c|}
\hline \multicolumn{3}{|c|}{ Grupo etário } & \multicolumn{2}{|c|}{ Sexo } & \multicolumn{2}{|c|}{ Total } \\
\hline 1 & 一 & 4 meses & 一 & - & - & - \\
\hline 4 & $1-$ & 12 meses & 1 & 2 & 3 & 1,5 \\
\hline 1 & $1-$ & 4 anos & 10 & 8 & 18 & 9,2 \\
\hline 4 & i- & 7 anos & 10 & 3 & 13 & 6,6 \\
\hline 7 & $1-$ & 10 anos & 11 & 7 & 18 & 9,1 \\
\hline 10 & $1-$ & 13 anos & 6 & 15 & 21 & 10,7 \\
\hline 13 & $1-$ & 16 anos & 11 & 11 & 22 & 11,2 \\
\hline 16 & $1-$ & 20 anos & 11 & 7 & 18 & 9,1 \\
\hline 20 & ! & 30 anos & 17 & 17 & 34 & 17,3 \\
\hline 30 & j- & 40 anos & 9 & 10 & 19 & 9,6 \\
\hline 40 & - & 50 anos & 7 & 7 & 14 & 7,1 \\
\hline 50 & - & 60 anos & 5 & 6 & 11 & 5,6 \\
\hline 60 & $1-$ & 70 anos & 3 & - & 3 & 1,5 \\
\hline 70 & - & 80 anos & - & 3 & 3 & 1,5 \\
\hline 80 & $1-$ & 90 anos & - & - & - & - \\
\hline \multicolumn{3}{|c|}{ Total } & $\begin{array}{r}101 \\
51,0 \%\end{array}$ & $\begin{array}{r}96 \\
49,0 \%\end{array}$ & 197 & $100,0 \%$ \\
\hline
\end{tabular}

T A B E L A 3

Distribuição populacional da amostra, segundo idade e sexo, zona urbana de Barra do Chapéu - 1970

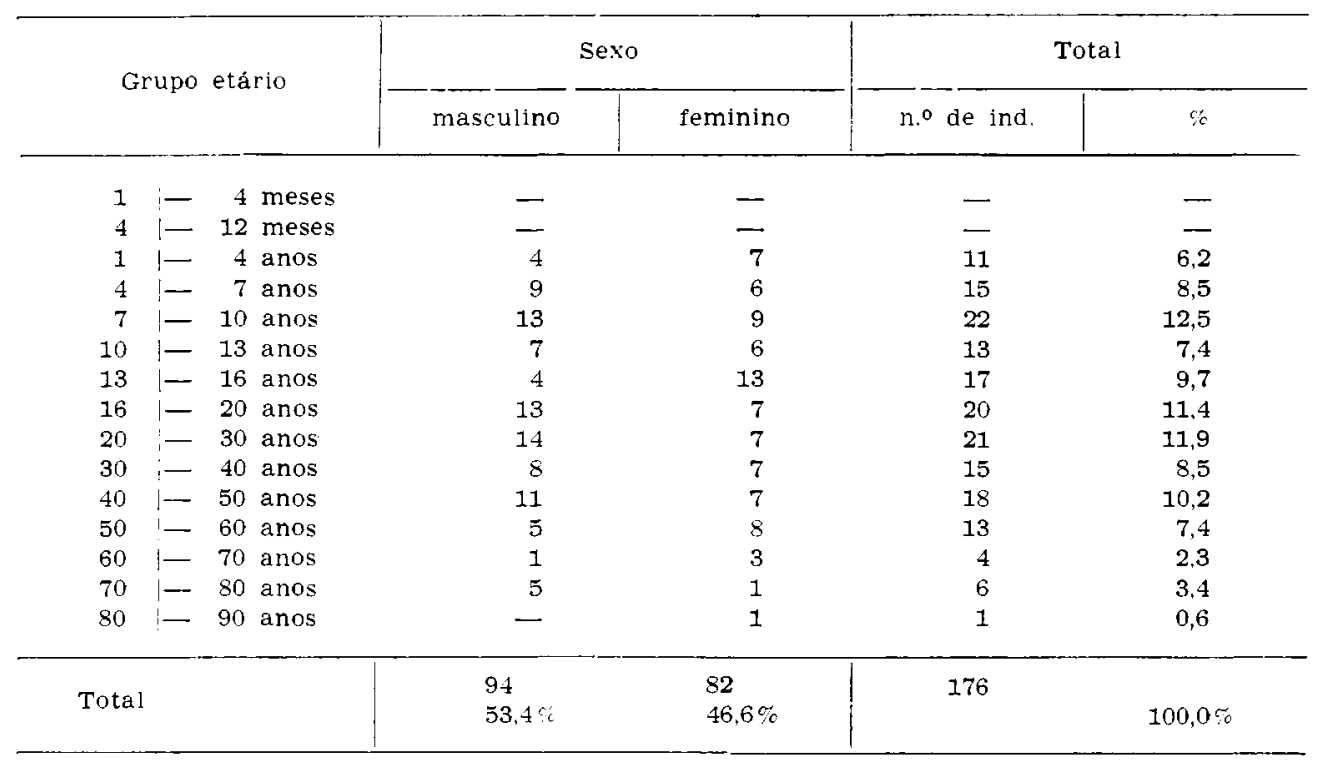


MIGUEL, M. \& BON, A. M. X. - Resultados do inquérito alimentar realizado nas cidades de Apial, Ribeira e Barra do Chapéu (São Paulo, Bras:l). Rev. Saúde prúbl., S. Paulo, 8: 75-86, 1974.

\section{T A B ELA 4}

Consumo médio diário de alimentos por individuo em Apial, Ribeira e Barra do Chapéu $-1970$

\begin{tabular}{l|c|c|c}
\hline Alimentos & $\begin{array}{c}\text { Ribeira } \\
(\mathrm{g})\end{array}$ & $\begin{array}{c}\text { Apiaj } \\
(\mathrm{g})\end{array}$ & $\begin{array}{c}\text { Barra do Chapéu } \\
(\mathrm{g})\end{array}$ \\
\hline
\end{tabular}

Cereais e Derivados:

Arroz polido
Bolacha
Farinha Láctea
Farinha de milho
Farinha de trígo
Flocos de milho
Fubá
Macarrāo
Maizena
Pão
Pípoca
Torrada

Leguminosas:

Feijão

Hortaliças:

Vegetais até $5 \%$ de hiarato de carbono:

116,8
0,4
0,5
14,0
18,8
-
1,9
15,5
0,1
53,2
0,4
-

64,0

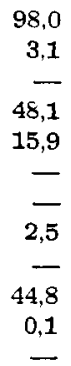

48,1

15,9

-

2,5

44,8

0,1

0,5
0,4

107,3

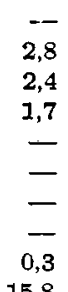

15,8

Vegetais ate $10 \%$ de hidrato de carbono:

Beterraba raiz

Cebola

Cenoura

Chuchu

Couve-flor

Couve-manteiga

Palmito

Pimentão

Repolho

- 1,9


MIGUEL, M. \& BON, A. M. X. - Resultados do inquérito alimentar realizado nas cidades de Aplal, Rlbeira e Barra do Chapéu (São Paulo, Brasil). Rev. Saúde públ., S. Paulo, 8: 75-86, 1974.

T A B E L A 4 (Continuação)

\begin{tabular}{l|c|c|c}
\hline Alimentos & $\begin{array}{c}\text { Ribeira } \\
(\mathrm{g})\end{array}$ & $\begin{array}{c}\text { Apiai } \\
(\mathrm{g})\end{array}$ & $\begin{array}{c}\text { Barra do Chapéu } \\
(\mathrm{g})\end{array}$ \\
\hline
\end{tabular}

Feculentos e derivados:

Batata doce

Batata inglesa

Cará

Ervilha fresca

Farinha de mandioca

Mandioquinha

Polvilho

Tapioca

Leite $e$ derivados:

Leite de cabra

Leite de vaca em pó

Leite de vaca $3 \%$ de gordura

Queijo

Frutas:

\section{Abacaxi \\ Banana \\ Coco \\ Jabuticaba \\ Laranja \\ Limäo \\ Maçã \\ Mamāo \\ Melancia \\ Pêssego}

Ovos:

Ovo de galinha

Ovo de pata

Carnes e produtos:

Caldo de carne

Carne de cabrito

Carne de Irango

Carne de peixes:

Bacalhau salgado

Peixe

Sardinha enlatada

Carne de porco

Carne de vaca
13,9

$\begin{array}{r}-- \\ 15,7 \\ -3,8 \\ 0,4 \\ 0,5 \\ 0,7 \\ 11,1 \\ 5,1 \\ \hline\end{array}$

0,9

18,2

-

20,8

0,4

3,9

11.8

3,8

$-$
11,9

2,7

11,4

0,1

- 4

13,5

3,3 
MIGUEL; M. \& BON, A. M. X. - Resultados do inquérito alimentar realizado nas cldades de Apiaf, Ribeira e Barra do Chapéu (São Paulo, Brasil). Rev. Saúde públ., \$. Paulo, 8: 75-86, 1974.

TABEA 4 (Continuação)

\begin{tabular}{l|c|c|c}
\hline Alimentos & $\begin{array}{c}\text { Ribeira } \\
(\mathbf{g})\end{array}$ & $\begin{array}{c}\text { Apiaí } \\
(\mathrm{g})\end{array}$ & $\begin{array}{c}\text { Barra do Chapéu } \\
(\mathrm{g})\end{array}$ \\
\hline \hline
\end{tabular}

Acricares e Doces:

Acúcar
Bananada
Doce de leite
Geléla de coco
Golabada
Rapadura
Sorvete
Xarope de groselha

Gorduras:

Banha

Manteiga

Margarina

oleo

Torresmo

Toucinho

Diversos:

$\begin{array}{lcc}72,2 & 81,8 & 79,4 \\ - & - & - \\ - & 0,1 & - \\ \overline{0}, 1 & 0,1 & 0,7 \\ \overline{0} & -1 & - \\ & - & - \\ & - & 0,1\end{array}$

$\begin{array}{rrr}22,1 & 9,7 & 32,0 \\ - & 1,7 & - \\ 0,8 & 4,4 & 0,1 \\ 7,1 & 20,1 & 6,2 \\ - & 0,4 & 0,5 \\ - & 0,4 & 0,7\end{array}$

Fonte: Baseado na Tabela de Composição de Allmentos, compllada de várias tabelas naclonais e estrangeiras pelo Departamento de Nutrição da Faculdade de Saúde Pública da Universidade de Sảo Paulo.

O consumo e necessidade médios diá- dadas, como pudemos verificar, não atinrios por indivíduos são apresentados na Tabela 5.

As Figuras 1, 2 e 3 mostram a adequa- dos os nutrientes, principalmente Cálcio, ção média das dietas nas 3 localidades. Vitamina $A$, Vitamina $B_{2}$ e Vitamina $C$.

COMENTARIOS E CONCLUSOES

O padrão alimentar das populações estugiu os valores ideais.

Encontramos deficiência de quase todos os nutrientes, principalmente Cálcio,
Vitamina A, Vitamina $B_{2}$ e Vitamina C. $O$ consumo de leite e queijo, considerados os maiores fornecedores de cálcio de uma dieta, foram quase nulos, mas isso pode ser justificado pela dificuldade 


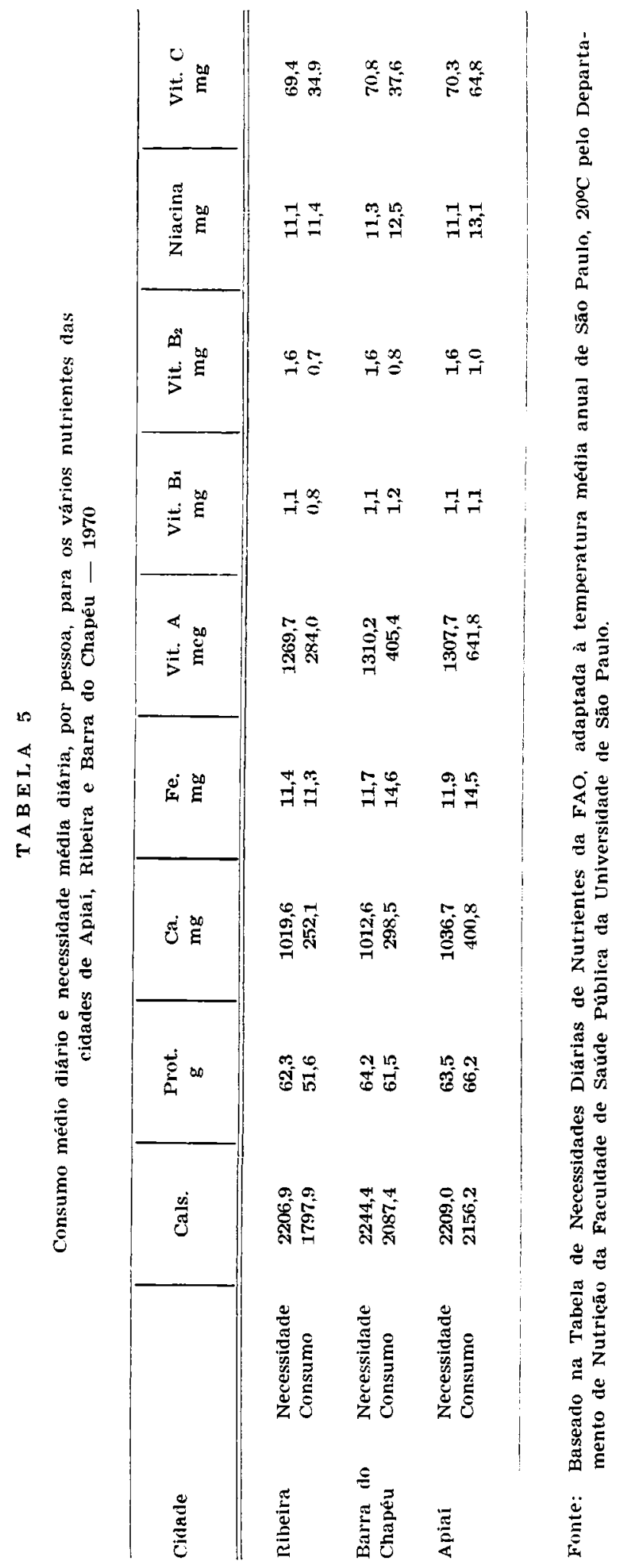




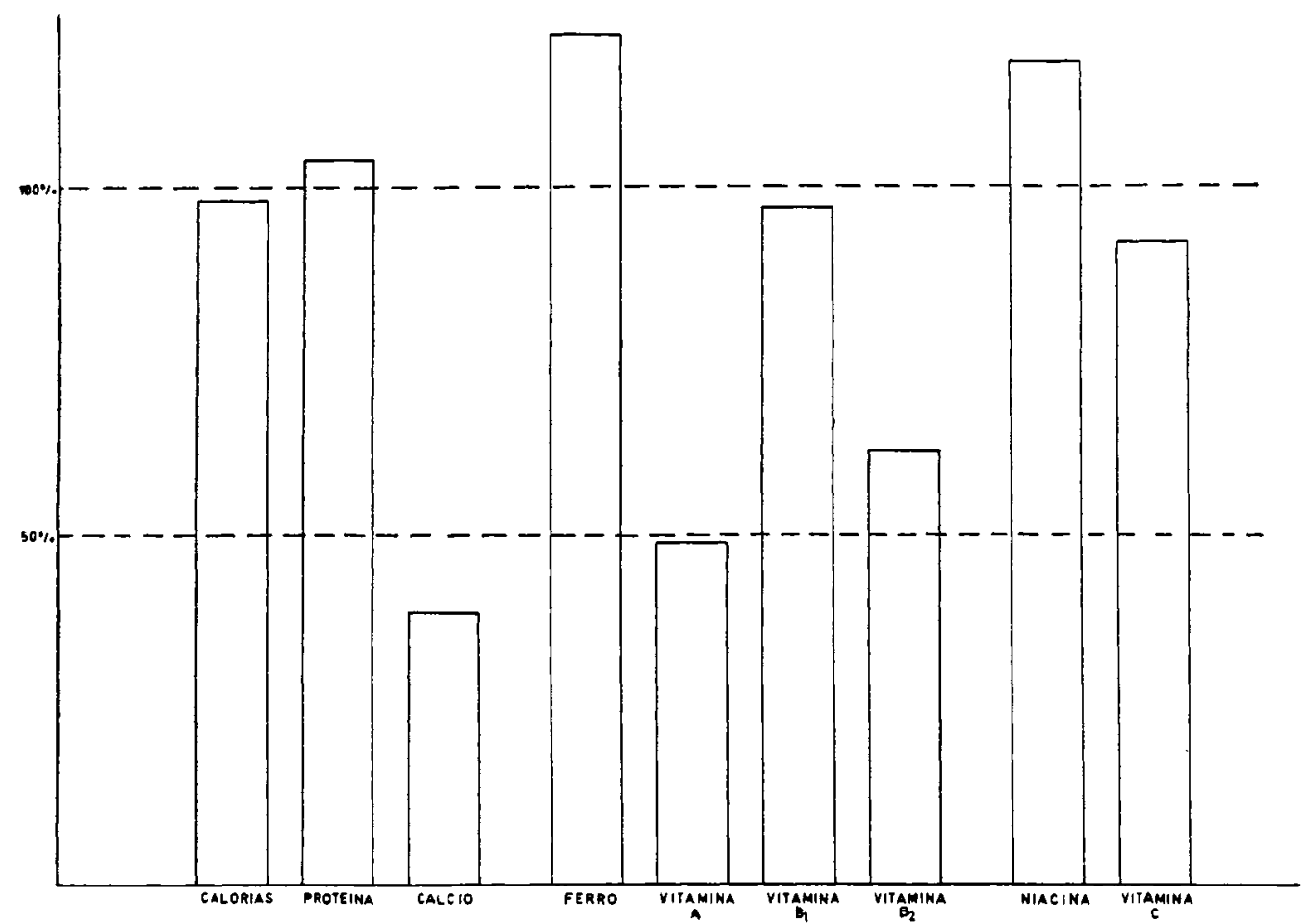

Fig. 1 - Porcentagem de adequação do consumo médio diário per capita, de nutrientes, verificados em Apiai, 1970.

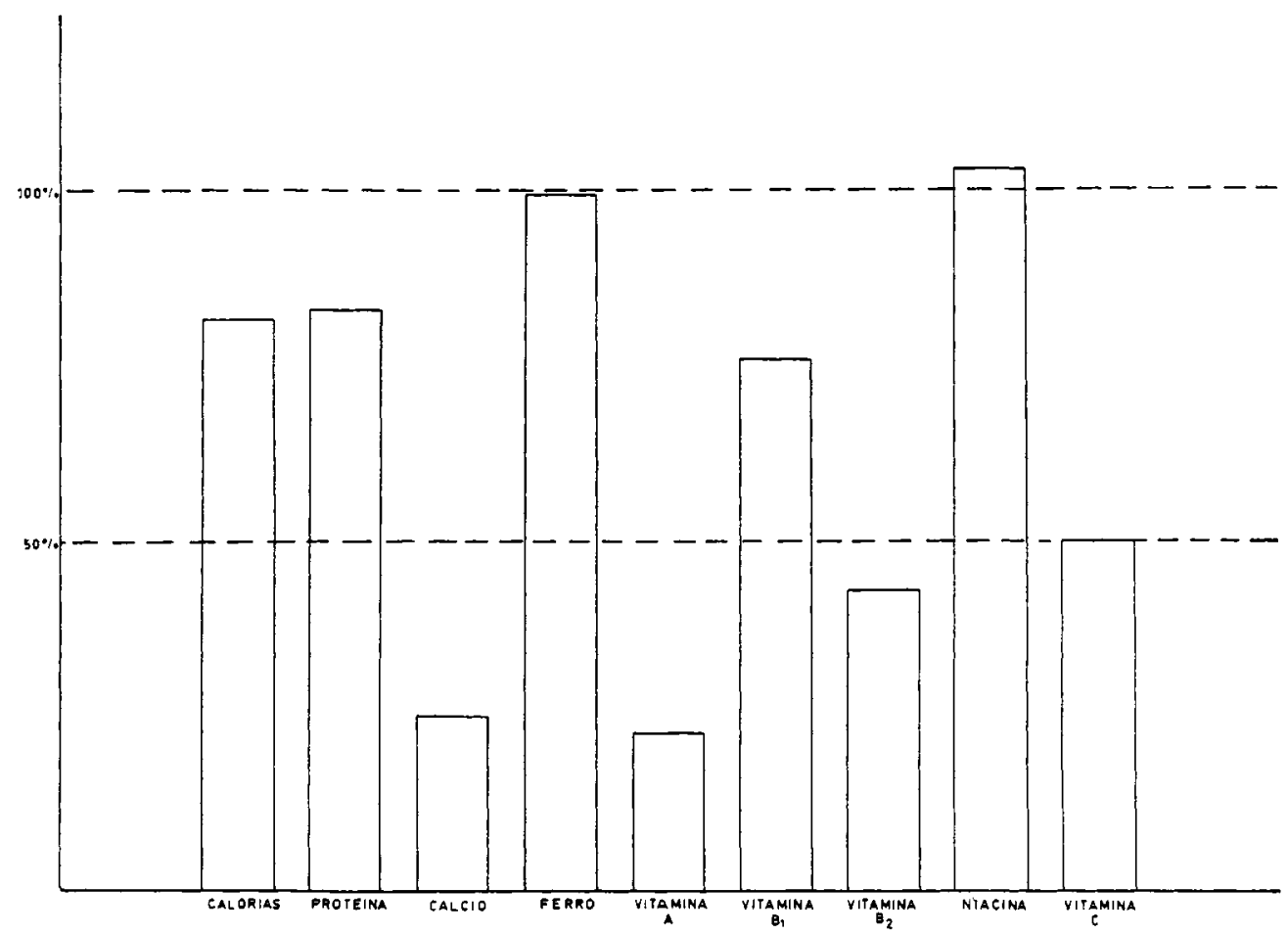

Fig. 2 - Porcentagem de adequação do consumo médio diário per capita, de nutrientes, verificados em Ribeira, 1970. 
MIGUEL, M. \& BON, A. M. X. - Resultados do inquérito allmentar realizado nas cldades de Aplal, Ribeira e Barra do Chapéu (Săo Paulo, Brasll). Rev. Saúde pribl., S. Paulo, 8: 75-86, 1974.

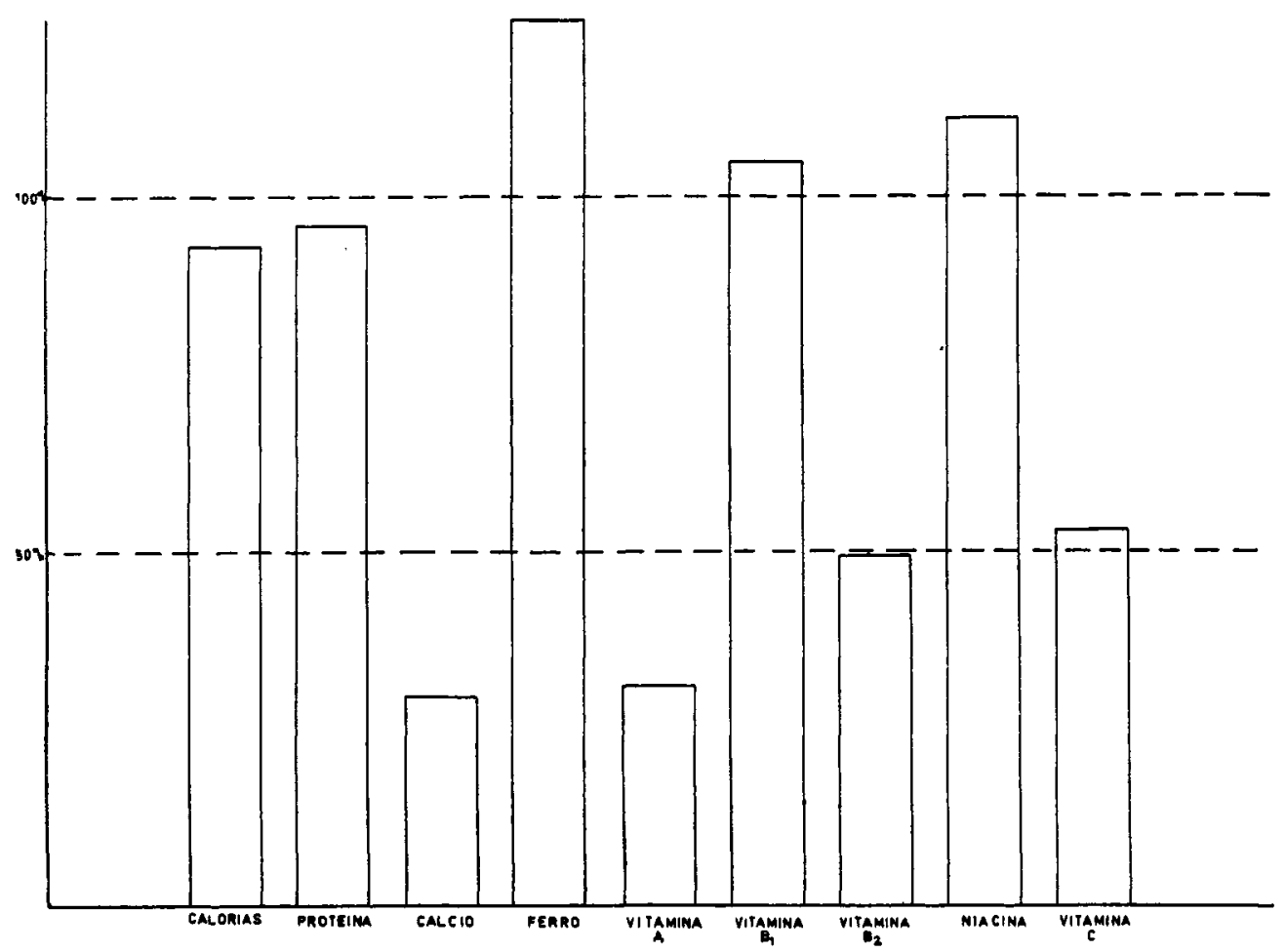

Fig. 3 - Porcentagem de adequaçáo do consumo médio diário per capita, de nutrientes, verificados em Barra do Chapéu, 1970.

que a população tem de encontrá-los, uma vez que a produção do leite no Vale do Ribeira é muito baixa.

No que se refere a Vitamina $A$, é de se estranhar a baixa adequação, pois Ribeira e Apiaí são consideradas cidades produtoras de mamão, alimento rico nesse nutriente. No entanto, a população consome em média, per capita, apenas 8 $g$ por dia dessa fruta que poderia cobrir grande parte das necessidades diárias.

Apesar do consumo de ferro ter sido bom nas 3 localidades, os inquéritos clínicos e bioquímicos, realizados pelo Departamento de Nutrição, constataram casos de anemia em Apiaí e Ribeira. Esses casos devem ser devidos a outros fatores co- mo verminose, problema de absorção e não à carência desse nutriente na alimentação.

Frutas e verduras, fontes de minerais e vitaminaş, não foram quase utilizados.

O consumo de carnes e ovos, produtos protéicos por excelência, apareceram em quantidades que estão longe de atingir o ideal.

Embora o poder aquisitivo tenha influência na alimentação de uma população, o fator principal para se melhorar o nível nutricional é o desenvolvimento de programas educativos de nutrição, com os quais são transmitidas noções básicas à grupos locais e técnicos da comunidade que atuarão como multiplicadores. 
MIGUEL, M. \& BON, A. M. X. - Resultados do inquérito alimentar realizado nas cidades de Apial, Ribeira e Barra do Chapéu (São Paulo, Bras.l). Rev. Saúde públ., S. Paulo, 8: 75-86, 1974.

Os cursos de educação alimentar teriam por finalidade a melhoria do nível de saúde, através do aproveitamento adequado dos alimentos, visando o equilíbrio da dieta familiar, e também estimulando o interesse pela organização de hortas, po- mares e criação de pequenos animais, possibilitando um maior consumo de hortaliças, frutas, carnes e ovos, contribuindo assim para diminuição das deficiências encontradas.

RSPU-B/206

Miguel, M. \& BON, A. M. X. - [The results of the nutrition survey carried out in the towns of Apiai, Ribeira and Barra do Chapéu (S. Paulo, Brazil)]. Rev. Saúde públ., S. Paulo, 8: 75-86, 1974

SUMMARY: There were presented the results of the nutrition survey carried out in the Region of Vale do Ribeira covering the towns of Apiai, Ribeira and the Village of Barra do Chapéu (Apiat) (S. Paulo, Brazil). The sample was made up of 154 families, corresponding to 939 persons. Data was gathered through the "one day-seven days" method. Analysing the data it was noticed that the recommended values where reached in Apiai only for protein, niacin and iron, in Barra do Chapéu, for iron, niacin, and thiamin and in Ribeira. only for niacin.

UNITERMS: Nutrition survey*; S. Paulo, Brazil*.

\section{REFERENCIAS BIBLIOGRAFICAS}

1. ENCICLOPEDIA dos municipios brasileiros. Rlo de Janeiro. IBGE, 1957. v. 28.

2. Ibidem, 1958. v. 30.

3. FUNDAÇAO IBGE - Sinopse preliminar do censo demográfico: São Paulo. Rio de Janeiro, 1971. (Recenseamento Geral do Brasil, 7.0, 1970).
4. SÃO PAULO (Estado) - Departamento de Aguas e Energia Elétrica. Serviço do Vale do Ribeira. Plano de desenvolvimento do Vale do Ribeira e Litoral Sul. Sāo Paulo, Brasconsult, 1966. $3 \mathrm{v}$.

Recebido para publicação em 17-12-1973. Aprovado para publicação em 21-1-1974. 